УДК 678.044:665.658.4

КАТАЛИЗАТОРЫ ДЕГИДРИРОВАНИЯ ЛЕГКИХ АЛКАНОВ

\title{
LIGHT ALKANE DEHYDROGENATION CATALYSTS
}

\author{
Р.И. Байрамгулова, Е.Ф. Трапезникова
}

Уфимский государственный нефтяной технический университет, г. Уфа, Российская Федерация

\author{
Rezeda I. Bairamgulova, Elena F. Trapeznikova \\ Ufa State Petroleum Technological University, \\ Ufa, Russian Federation \\ e-mail: rezeda_bairamgulova@mail.ru
}

Аннотация. Дегидрирование является одним из значимых процессов в нефтехимии, в результате которого получают олефины, представляющие большую ценность в качестве мономеров для производства синтетического каучука и пластмасс, синтеза высокооктановых компонентов бензина и других ценных химических продуктов.

В данной обзорной статье проведен анализ известных промышленных и разработанных катализаторов дегидрирования легких алканов. Рассмотрены катализаторы на основе платины, алюмохромовые, железооксидные, оксидомолибденовые и оксидованадиевые катализаторы. Для каждого из них представлены соответствующие свойства, компонентный состав, сырье, области применения, а также достоинства и недостатки. Рассматривались различные разработки по использованию промоторов в виде металлов или оксидов металлов, повышающие конверсию и селективность процесса дегидрирования. Также были описаны носители катализаторов, позволяющие увеличить стабильность в условиях высоких температур во время процесса дегидрирования и 
регенерации катализатора путем выжига кокса. Данная работа была проведена для выявления наиболее эффективных и стабильных катализаторов для дегидрирования легких алканов.

Abstract. Dehydration is one of the significant processes in the petrochemical industry, as a result of which olefins are obtained, which are of great value as monomers for the production of synthetic rubber and plastics, the synthesis of high-octane components of gasoline and other valuable chemical products.

This review analyzes the known industrial and developed catalysts for the dehydrogenation of light alkanes. Catalysts based on platinum, aluminum chromium, iron oxide, oxide-molybdenum and vanadium oxide catalysts are considered. For each of them, the corresponding properties, component composition, raw materials, fields of application, as well as advantages and disadvantages are presented. Various developments on the use of promoters in the form of metals or metal oxides, which increase the conversion and selectivity of the dehydrogenation process, were considered. Catalyst carriers have also been described that allow for increased stability under high temperature conditions during the dehydrogenation process and catalyst regeneration by burning the coke. This work was carried out to identify the most effective and stable catalysts for the dehydrogenation of light alkanes.

Ключевые слова: дегидрирование, промотор, селективность, стабильность, конверсия, носитель, катализатор

Key words: dehydrogenation, promoter, selectivity, stability, conversion, carrier, catalyst 


\section{Введение}

Процесс дегидрирования используется для получения олефиновых углеводородов, преимущественно из алканов $\mathrm{C}_{3}-\mathrm{C}_{5}$. Олефины являются важным сырьем, которое используется для производства широкого спектра химических веществ, включая полимеры (полиэтилен и полипропилен), оксигенаты (этиленгликоль, ацетальдегид, ацетон и пропиленоксид) и важные химические промежуточные соединения (этилбензол и пропиональдегид). В связи с этим рост производства олефиновых углеводородов на мировом рынке постоянно растет.

В настоящее время для проведения процесса дегидрирования используются процессы Catofin и Catadiene со стационарным слоем катализатора, процессы STAR и Oleflex c движущимся слоем и отечественный процесс Ярсинтез с псевдоожиженным слоем катализатора в реакторе, который получил наибольшее распространение в нашей стране.

Для дегидрирования парафиновых углеводородов применяются катализаторы различной природы и состава. Механизм действия катализатора дегидрирования состоит из следующих стадий: адсорбция углеводорода на координационно-ненасыщенном центре; разрыв C-H- связи, в результате чего возникает связь с поверхностью катализатора; образование ненасыщенного углеводорода с десорбцией с поверхности катализатора.

Катализаторы дегидрирования делятся на три группы:

1) металлы VIII группы (Fe, $\mathrm{Co}, \mathrm{Ni}, \mathrm{Pd}, \mathrm{Pt})$ и ІБ подгруппы (Cu, $\mathrm{Ag})$ периодической системы;

2) оксиды металлов (MgO, $\left.\mathrm{ZnO}, \mathrm{Cr}_{2} \mathrm{O}_{3}, \mathrm{Fe}_{2} \mathrm{O}_{3}, \mathrm{VOx}\right)$;

3) сложные оксидные и сульфидные катализаторы, состоящие из смеси оксидов (медь- и цинкхромоксидные $\mathrm{CuO} \cdot \mathrm{Cr}_{2} \mathrm{O}_{3}$ и $\mathrm{ZnO} \cdot \mathrm{Cr}_{2} \mathrm{O}_{3}$, кобальтмолибденоксидные $\mathrm{CoO} \cdot \mathrm{MoO}_{3}$ никельИ кобальтвольфрамоксидные $\mathrm{NiO} \cdot \mathrm{WO}_{3}, \mathrm{CoO} \cdot \mathrm{WO}_{3}$ ) или сульфидов. 
Необходимая глубина производства олефинов, которая составляет 40-50 \%, достигается при дегидрировании алканов интервале температур 773-783 К. Такая высокая температура создает благоприятные условия для протекания побочных процессов, таких как коксообразование, крекинг и другие. В связи с этим промышленные катализаторы должны обладать высокой селективностью, активностью и стабильностью в условиях окислительно-восстановительной среды, необходимой степенью регенерируемости путем многократного выжига кокса с поверхности катализатора. Помимо этого катализаторы должны обладать высокой механической прочностью и теплоемкостью в зависимости от условий эксплуатации. Для достижения данных требований катализаторы часто наносят на пористые носители и добавляют различные промоторы в виде чистых металлов или оксидов металлов.

\section{Платиновые катализаторы}

Платина является единственным благородным металлом VIII группы, используемым в промышленности благодаря своей превосходной способности к разрыву связей С-Н и низкой активности по отношению к C-С-связям. Однако платина имеет существенные недостатки. В процессе дегидрирования происходит дезактивация катализатора, которая вызывается за счет побочных реакций. В первую очередь происходит образование углеродных отложений на поверхности катализатора, приводящих к снижению активности, поэтому катализатор необходимо часто регенерировать путем выжигания отложений кокса, однако высокая температура вызывает агломерацию или спекание наночастиц платины $[1,2]$.

Для устранения этих недостатков стали использовать носители для катализатора, которые должны быть термически стабильными и иметь ограниченную кислотность в суровых условиях на стадии регенерации. И наконец, для оптимального распределения частиц платины 
предпочтительны относительно большая площадь поверхности и равномерное распределение пор по размерам.

Оксид алюминия с большой площадью поверхности является классическим носителем, используемым в катализаторах дегидрирования на основе платины. Он обладает такими достоинствами, как высокая термостойкость, механическая прочность и исключительная способность сохранять диспергированные наночастицы платины, которые имеют решающее значение для достижения стабильной работы катализатора. Тем не менее, большинство носителей из оксида алюминия являются кислотными, и поэтому для ограничения кислотности носителей используются промоторы. Добавление щелочных металлов, таких как Li, $\mathrm{Na}$ и K, отравляет эти кислотные центры, подавляя образование кокса. Кроме того, эти промоторы могут модифицировать свойства платины и подавлять побочные реакции, такие как гидрогенолиз и изомеризация. Zn и $\mathrm{Mg}$ также используются в качестве промоторов, которые позволяют увеличить термическую стабильность катализатора и снизить спекание платины в результате сильного взаимодействия металла с подложкой.

За счет добавления олова в катализатор Pt-Sn происходит значительное увеличение стабильности катализатора, селективности процесса и дисперсности в результате уменьшения коксообразования. В такой системе между оловом и платиной происходит постоянный обмен электронами, что ведет к ослаблению связи $\mathrm{Pt}-\mathrm{C}$, в результате чего уменьшается закококсовываемость катализатора и увеличивается его срок службы [3, 4].

Известен катализатор дегидрирования углеводородов $\mathrm{C}_{2}-\mathrm{C}_{5}$, включающий цеолит типа пентасил, модифицированный 10-14 \% масс. хрома, а также щелочной металл в количестве 0,2-3,4 \% масс. Достоинством такого катализатора является увеличение выхода олефинов. Однако существенными недостатками являются присутствие токсичных соединений хрома, а также сложность приготовления катализатора [5]. 
Авторами патента [6] была разработана катализаторная композиция, где в качестве основного компонента используется платина вместе с небольшим содержанием олова и калия $(0,9-1,1 \%)$, нанесенная на оксид алюминия тета-модификации. Недостатком является большое количество кокса, образующегося на алюмооксидных подложках, и небольшая термическая устойчивость.

В работе [7] предложено использование катализатора, содержащего в качестве активного компонента платину, нанесенного на деалюминированный цеолит структурного типа BEA с соотношением $\mathrm{SiO}_{2} / \mathrm{Al}_{2} \mathrm{O}_{3}$ более 600. Такой катализатор заполняет реактор с неподвижным слоем, процесс проводится при температуре 550-600 ${ }^{\circ} \mathrm{C}$. Техническим результатом является увеличение селективности процесса при низком коксообразовании.

Процесс дегидрирования, в котором используются платиновые катализаторы марки DEH, проводят в среде водородсодержащего газа для снижения образования кокса и увеличения селективности целевого олефина. Платиновые катализаторы дегидрирования применяются в таких процессах, как «Oleflex», «STAR» и «PDH». Процесс «Oleflex» для дегидрирования парафинов осуществляется в последовательно соединенных адиабатических реакторах с промежуточным подводом тепла между ступенями за счет нагрева парогазового потока. Процесс «STAR» проводится в обогреваемых трубчатых реакторах. Процесс «PDH» также осуществляется на платиновом катализаторе, нанесенном на алюмомагниевую шпинель [8].

\section{Алюмохромовые катализаторы}

Наибольшее распространение в процессе дегидрирования парафиновых углеводородов приобрел алюмохромовый катализатор, где входящий в состав оксид хрома способен к активной адсорбции водорода. Однако оксид хрома в чистом виде обладает термической нестабильностью при 
температурах выше $350{ }^{\circ} \mathrm{C}$, в результате чего происходит переход в неактивный $\alpha-\mathrm{Cr}_{2} \mathrm{O}_{3}$. Благодаря использованию оксида алюминия в качестве носителя происходит стабилизация оксида хрома. Несмотря на токсическое действие шестивалентного хрома, использование технологии дегидрирования на алюмохромовых катализаторах оправдывается более низкой стоимостью таких катализаторов $[9,10]$.

Природа носителя важна не только потому, что он регулирует на механические свойства катализатора, но также и потому, что взаимодействие носителя с активной фазой может оказывать глубокое влияние на активность и селективность катализатора. Глинозем является наиболее распространенным носителем, и было исследовано множество способов получения хромо-глиноземных катализаторов, который демонстрирует превосходную термостабильность и очень активен для дегидрирования изобутана [11].

Однако использование глинозема в качестве подложки не лишено недостатков. Например, $\mathrm{Al}_{2} \mathrm{O}_{3}$ может катализировать крекинг и коксование из-за его поверхностной кислотности, что приводит к снижению как активности, так и селективности. Решением этой проблемы является легирование катализаторов дегидрирования на основе оксида алюминия щелочными ионами, которые могут эффективно отравить эти нежелательные кислотные центры.

Известно, что щелочные металлы, такие как $\mathrm{K}, \mathrm{Rb}$ и $\mathrm{Cs}$, способствуют повышению активности и селективности катализаторов дегидрирования на основе хрома. Это явление объясняется способностью крупных щелочных катионов стабилизировать структуру носителя, снижать поверхностную кислотность и увеличивать число активных участков хрома. Кроме того, присутствие промоторов щелочных металлов увеличивает дисперсию активной фазы, способствуя образованию в окислительных условиях комплексов $\mathrm{Cr}^{6+}$, которые впоследствии приводят к образованию $\mathrm{Cr}^{3+}$ в восстановительной атмосфере [12]. 
В течение каталитического цикла алюмохромовые катализаторы дегидрирования теряют свою активность из-за осаждения кокса, и, как и в случае с катализаторами на основе $\mathrm{Pt}$, их необходимо периодически регенерировать. Хотя катализаторы восстанавливают большую часть своей активности после каждого цикла регенерации, потеря активности не является полностью обратимой. Это связано с тем, что тепло, выделяемое при сжигании кокса во время регенерации, приводит к включению хрома в каркас из оксида алюминия и, следовательно, к уменьшению количества каталитически активных частиц хрома с каждой стадией регенерации [13].

Наибольший выход $\mathrm{C}_{3}-\mathrm{C}_{5}$-олефинов при использовании алюмохромовых катализаторов достигается при поверхностной концентрации оксида хрома (III) 5-10 мкмоль/м². При добавлении щелочных промоторов поверхностная концентрация оксида хрома может возрастать до 12 мкмоль/м² вследствие диспергирования оксида хрома (III) [14].

Для использования в качестве носителя алюмохромового катализатора, продукта термохимической активации $\mathrm{Al}(\mathrm{OH})_{3}$, установлен интервал концентраций $\mathrm{Cr}_{2} \mathrm{O}_{3}$ (9 \% мол.) и $\mathrm{K}_{2} \mathrm{O}$ (1,7-2,2 \% мол.) в катализаторе реакции дегидрирования изобутана, в результате которой достигнута селективность по изобутилену 87-88 \% масс. $[15,16]$.

Авторами патента [17] разработан способ получения высокоэффективного алюмохромового катализатора с использованием СВЧ-излучения. Такой катализатор отличается высокими эксплуатационными и каталитическими свойствами, к которым относятся термическая стабильность, высокая механическая прочность и низкие истирающие способности. Благодаря воздействию сверхвысокочастотного поля на стадиях пропитки алюмооксидного носителя и сушки катализатора получают более высокие показатели процесса дегидрирования, где выход и селективность олефинов повышается на 4,3 \% и 3,8 \% соответственно. Такой модифицированный катализатор предпочтительно использовать для 
дегидрирования изобутана и изопентана. Наибольшая активность разработанного катализатора проявляется при температуре $540{ }^{\circ} \mathrm{C}$ [18-21].

В Институте катализа СО РАН проводились эксперименты по дегидрированию смеси пропана и изобутана в кипящем слое на новом алюмохромовом катализаторе $\mathrm{Cr}_{2} \mathrm{O}_{3} / \mathrm{Al}_{2} \mathrm{O}_{3}$. Эксперимент проводился в двух вариантах процесса: при постоянной объемной скорости как по индивидуальному парафину, так и их смеси и при постоянной объемной скорости по индивидуальному парафину в смеси. Проведенные эксперименты по дегидрированию смеси парафинов показали, что если необходимо получить преимущественно бутены, то необходимо проводить дегидрирование пропан-бутановой смеси или ШФЛУ. Для направления процесса в сторону получения пропилена необходимо использовать смесь метана и пропана, ПНГ или его смесь с ШФЛУ. В результате проведения экспериментов были получены следующие результаты:

- получение более высокой конверсии $\mathrm{C}_{3}-\mathrm{C}_{5}$ парафинов в олефины;

- увеличение суммарной селективности процесса по олефинам;

- отсутствие необходимости разделения углеводородов;

- увеличение выхода пропилена в товарном продукте [22, 23].

В патенте [24] предлагается катализатор дегидрирования, который изготавливают в процессе термоактивации гидратированного продукта термохимической активации гидраргиллита совместно с соединениями хрома, циркония, щелочного металла, оксидов титана, циркония и гафния. Показано присутствие пяти форм хрома в катализаторах данного типа: две формы $\mathrm{Cr}^{6+}$ и три формы $\mathrm{Cr}^{3+}$. На основании результатов был сделан вывод о том, что каталитическая активность катализаторов в реакции дегидрирования изобутана обеспечивается высокодисперсными частицами $\mathrm{Cr}^{3+}$, которые возникают при содержании хрома в катализаторе приблизительно 7-9 \% масс. Данный катализатор обладает более высокой механической прочностью, каталитической активностью, селективностью и стабильностью. 
Процессы дегидрирования происходят с рециркуляцией непрореагировавшего сырья, поскольку степень превращения углеводородов является небольшой. Такое действие приводит к дополнительным энергетическим затратам. Для уменьшения рециркуляции углеводородов предлагают использовать алюмохромовые катализаторы, которые также содержат оксиды циркония и бора, которые способствуют более полному превращению углеводородов [25].

В работах [26-31] описаны различные катализаторы, содержащие оксид хрома и различные оксиды переходных металлов, нанесенные на оксид алюминия. Техническим результатом таких катализаторов является более высокая конверсия парафинов, достигается более глубокая суммарная конверсия парафинов в олефины, а также увеличивается суммарная селективность процесса.

\section{Железооксидные катализаторы}

Исследовательской лабораторией $\mathrm{AO}$ «Каучук» проведены исследования по экструзионному формированию фигурных железооксидных катализаторов дегидрирования. Пасты катализатора с влажностью не более 16-18 \% подвергали экструзионному формированию, сушке и прокаливанию полученных экструдатов. Для сравнения образцы обычного и фигурного катализаторов экструдировали из одной смеси в одинаковых условиях. Анализ сырья и продуктов проводили с помощью газожидкостной хромотографии. Эксперимент показал, что фигурные железнооксидные гранулы катализатора обладают более высокой удельной поверхностью, а их активность на 2-3 \% выше по сравнению с промышленными катализаторами. При увеличении диаметра гранул происходит снижение гидравлического сопротивления слоя за счет увеличения его порозности $[32,33]$.

Синтезированы $\mathrm{Fe} / \mathrm{SiO}_{2}$ и $\mathrm{Fe}-\mathrm{Mo} / \mathrm{SiO}_{2}$ катализаторы с соотношением металлов. В эксперименте в качестве сырья использовали смесь $\mathrm{C}_{2}-\mathrm{C}_{4}$ при 
различных соотношениях углеводородов. Процесс проводили в проточном кварцевом реакторе с неподвижным слоем катализатора при атмосферном давлении. Результаты эксперимента показали, что при проведении процесса со скоростью подачи сырья 500 ч $^{-1}$ и температуре 923 К увеличивается конверсия СНГ до 96,3-96,9 \%. При добавлении молибдена в качестве промотора до 50 \% возрастает суммарный выход олефинов до 63,3 \% [34].

\section{Оксидованадиевые катализаторы}

Несмотря на отличные характеристики катализаторов на основе платины и оксида хрома при дегидрировании парафинов, кроме ряда проблем, включая отравление катализатора, высокую стоимость платины и экологические проблемы, связанные с использованием шестивалентного хрома, привело к стимулированию поиска альтернатив. Исследования катализаторов дегидрирования на основе ванадия начались в 1980-х годах, хотя в то время основное внимание уделялось окислительному дегидрированию с использованием ванадий-магниевых смешанных оксидов [35].

Характер присутствия ванадия в катализаторе в значительной степени зависит от типа носителя, площади поверхности носителя, загрузки металла и степени окисления ванадия. В качестве носителя для оксида ванадия предложен глинозем, хотя в результате испытаний широкого спектра носителей на основе $\mathrm{Si}$ и $\mathrm{Al}$ был сделан вывод о том, что использование кремнезема для легирования носителя оказывает благоприятное влияние на стабильность и активность катализатора. Также было показано, что эффективность нанесенных ванадиевых катализаторов может быть улучшена за счет добавления $\mathrm{MgO}$ либо в качестве промотора, либо в качестве компонента смешанного оксида [36].

\section{Оксидомолибденовые катализаторы}

Оксиды молибдена также часто используются в качестве катализаторов в реакциях конверсии углеводородов, включая дегидрирование. Впервые 
сведения о дегидрогенизирующей активности катализатора на основе оксида молибдена $\mathrm{MoO}_{3} / \mathrm{Al}_{2} \mathrm{O}_{3}$ были опубликованы в 1946 году. Однако неокислительное дегидрирование алканов на $\mathrm{MoO}_{\text {х }}$ изучалось мало, так как акцент был сделан на изучение окислительного дегидрирования на этих катализаторах. Оптимальная активность катализаторов была достигнута при однослойном покрытии оксида молибдена на носителе из оксида алюминия. В свежем катализаторе молибден присутствует в виде $\mathrm{Mo}^{6+}$, но, аналогично катализаторам, содержащим оксид ванадия и хрома, $\mathrm{MoO}_{3}$ восстанавливается за счет углеводородного сырья во время реакции для создания активных частиц [37].

Катализатор на основе оксида молибдена дезактивируется из-за образования каталитически неактивных кристаллитов $\mathrm{Al}_{2}\left(\mathrm{MoO}_{4}\right)_{3}$. Для предотвращения образования этого смешанного оксида добавляют оксид магния, который также обладает активностью к дегидрированию. Было обнаружено, что дополнительный полезный эффект от добавления оксида магния заключается в том, что полученный смешанный оксид имеет более низкую кислотность, что повышает селективность по алкену и уменьшает осаждение кокса. Восстановление катализатора водородом перед реакцией увеличивает конверсию, хотя селективность уменьшается из-за образования кислотных центров. В целом, катализаторы $\mathrm{MoO}_{3}$ быстро дезактивируются из-за коксования и обычно обеспечивают относительно низкую конверсию и селективность [38].

\section{Выводы}

В данной статье были проанализированы катализаторы процесса дегидрирования различной природы и состава. Первым промышленным катализатором для дегидрирования алканов является платина, нанесенная на различные пористые носители с добавлением промоторов. Однако даже при использовании носителей не совсем были устранены такие недостатки, как образование кокса на поверхности катализатора и спекание частиц 
платины под действием высоких температур. В связи с этим наиболее распространена катализаторная композиция на основе Pt-Sn, которая не только устраняет эти недостатки, но и увеличивает выход олефинов в процессе дегидрирования. Однако минусом такого катализатора является сложность его приготовления.

Алюмохромовые катализаторы получили наибольшее распространение преимущественно в нашей стране в процессе дегидрирования парафинов. Благодаря оксиду хрома процесс можно вести при повышенных температурах, что характеризует его высокую термостабильность. В качестве носителя используется оксид алюминия, позволяющий стабилизировать катализатор и увеличить его активность при дегидрировании. Для уменьшения коксообразования вводят промоторы в виде различных щелочных ионов металлов. Все разработки такого катализатора различаются лишь тем, что варьируется содержание оксида хрома и промоторов. Такие модифицированные катализаторы позволяют увеличить суммарную глубину конверсии парафинов. Поэтому использование алюмохромовых катализаторов в настоящее время остается наиболее стабильным и надежным способом дегидрирования, включая их низкую стоимость по сравнению с платиновыми катализаторами.

Железооксидные катализаторы отличаются сложностью приготовления, что отводит их использование на задний план, хотя они обладают высокой удельной поверхностью и являются более активным, чем промышленные катализаторы. Также достоинством такого катализатора является ведение процесса дегидрирования с использованием водяного пара при повышенной температуре, которая не будет влиять на активность катализатора.

Поскольку катализаторы на основе платины и оксида хрома имеют такие недостатки, как высокая стоимость платины и вредное воздействие шестивалентного хрома с точки зрения экологии, были разработаны катализаторы на основе оксида ванадия и оксида молибдена, которые 
решают данные проблемы. Однако такие катализаторы быстро теряют свою активность из-за образования кокса на поверхности и обеспечивают недостаточную конверсию парафинов по сравнению с традиционными катализаторами.

\section{Список используемых источников}

1. Rioux R.M., Song H., Hoefelmeyer J.D., Yang P., Somorjai G.A. HighSurface-Area Catalyst Design: Synthesis, Characterization, and Reaction Studies of Platinum Nanoparticles in Mesoporous // J. Phys. Chem. B. 2005. № 109(6). P. 2192-2202.

2. Caspary K.J., Gehrke H., Heinritz-Adrian M., Schwefer M. In Handbook of Heterogeneous Catalysis. 2008. P. 3206-3229.

3. Sanfilippo D. Dehydrogenation of Paraffins: Synergies between Catalyst Design and Reactor Engineering // Catalysis Today. 2006. № 111. 133 p.

4. Степанова Л.Н., Бельская О.Б., Лихолобов В.А. Синтез и исследование катализаторов $\mathrm{Pt} / \mathrm{MgAlSnO} / /$ Химия в интересах устойчивого развития. 2014. № 1. С. 61-68.

5. Пат. 2463109 РФ, МПК В 01 J 29/48, В 01 J 21/04, В 01 J 21/08, В 01 J 23/04, В 01 J 37/02, В 01 J 37/30, С 07 C 5/333. Катализатор дегидрирования, способ его получения и способ получения олефиновых углеводородов $\mathrm{C}_{2}-\mathrm{C}_{5} \quad \mathrm{c}$ использованием этого катализатора / В.Е. Вахмистров, А.Б. Пономарёв, М.В. Шостаковский, В.Н. Калинин. 2011106085/04, Заявлено 18.02.2011; Опубл. 10.10.2012. Бюл. 28.

6. Пат. 6756340 US, МПК В 01 J 23/00, В 01 J 23/38, В 01 J 23/54, В 01 J 23/56, B 01 J 23/58. Dehydrogenation Catalyst Composition / T.V. Voskoboynikov, J.W. Adriaan Sachtler, D.H. Wei, B.V. Vora. Заявлено 08.04.2002; Опубл. 29.06.2004. 
7. Пат. 2638171 РФ, МПК С 07 C 5/333, В 01 J 37/30, В 01 J 29/74, В 01 J 29/068, В 01 J 23/14. Катализатор дегидрирования сжиженных углеводородных газов, способ его получения и применения / А.В. Смирнов, И.И. Иванова, Г.Г. Иванушкин. 2016140486, Заявлено 14.10.2016; Опубл. 12.12.2017. Бюл. 35.

8. Буянов А.В. Катализаторы и процессы дегидрирования парафинов и олефинов // Кинетика и катализ. 2001. № 1. С. 72-85.

9. Каримов О.Х., Даминев Р.Р., Касьянова Л.З., Каримов Э.Х. Модифицирование алюмооксиного носителя для катализатора дегидрирования легких углеводородов под действием СВЧ-поля // Башкирский химический журнал. 2012. № 4. С. 7-10.

10. Диденко Л.П., Колесникова А.М., Воронецкий М.С., Савченко В.И., Домашнев И.А., Семенцова Л.А. Алюмохромовый катализатор дегидрирования пропана, приготовленный модифицированным методом соосаждения // Катализ в промышленности. 2011. № 2. С. 7-14.

11. Zhao H., Song H., Xu L., Chou L. Isobutane Dehydrogenation over the Mesoporous $\mathrm{Cr}_{2} \mathrm{O}_{3} / \mathrm{Al}_{2} \mathrm{O}_{3}$ Catalysts Synthesized from a Metal-Organic Framework MIL-101 // Applied Catalysis A: General. 2013. No. 456. P. 188-196.

12. Marcilly C., Delmon B. J. The Activity of True $\mathrm{Cr}_{2} \mathrm{O}_{3} / \mathrm{Al}_{2} \mathrm{O}_{3}$ Solid Solutions in Dehydrogenation // Journal of Catalysis. 1972. No. 2. P. 336-347.

13. Weckhuysen B.M., Schoonheydt R.A. Alkane Dehydrogenation over Supported Chromium Oxide Catalysts // Catalysis Today. 1999. No. 2. P. 223-232.

14. Bhasin M.M. Dehydrogenation and Oxydehydrogenation of Paraffins to Olefins // Appl. Catalysis A: General. 2001. Vol. 221. P. 397-419.

15. Гильманов X.X. Применение продуктов термохимической активации глинозема в качестве носителей микросферических алюмохромовых катализаторов дегидрирования $\mathrm{C}_{3}-\mathrm{C}_{5}$ парафинов // Вестник Казанского технологического университета. 2010. № 2. С. 355-363. 
16. Нестеров О.Н., Егорова С.Р., Бекмухамедов Г.Э., Катаев А.Н., Ламберов А.А., Гильманов Х.Х. Влияние концентраций оксидов хрома и калия на свойства микросферического алюмохромового катализатора дегидрирования низших парафинов // Вестник Казанского технологического университета. 2011. № 5. С. 33-39.

17. Пат. 2539300 РФ, МПК В 01 J 37/34, В 01 J 37/02, C 07 C 5/333. Способ приготовления катализатора для дегидрирования парафиновых углеводородов / О.Х. Каримов, Р.Р. Даминев, Л.З. Касьянова, Э.Х. Каримов. 20141008174/04, Заявлено 10.01.2014; Опубл. 20.01.2015. Бюл. 2.

18. Karimov O.K., Daminev R.R., Kasyanova L.Z. Increase in ThermoStability of Chromia-Alumina Catalysts Used in Dehydrogenation of Paraffines by Means SHF Radiation // Middle East Journal of Scientific Research. 2013. No. 2. P. 127-130.

19. Karimov O.K., Karimov E.K., Daminev R.R., Kasyanova L.Z., Nasyrov R.R. Power-Efficient Synthesis of Isoprene via Two-Stage Dehydrogenation of Isopentane // World Applied Sciences Journal. 2013. No. 3. P. 320-325.

20. Касьянова Л.3., Каримов О.Х., Каримов Э.Х. Регулирование физико-химических свойств термоактивированного тригидрата алюминия // Башкирский химический журнал. 2014. № 3. С. 90-94.

21. Каримов О.Х., Даминев Р.Р., Касьянова Л.З., Каримов Э.Х., Вахитова P.P. Исследование процесса сушки алюмохромового катализатора в электромагнитном поле СВЧ диапазона // Электронный научный журнал «Нефтегазовое дело». 2013. № 4. С. 291-301. URL: www.ogbus.ru/autors/karimovokh/karimovokh_1.pdf (дата обращения: 12.04.2019).

22. Пахомов Н.А. Дегидрирование парафинов $\mathrm{C}_{2}-\mathrm{C}_{4}$ на $\mathrm{Cr}_{2} \mathrm{O}_{3} / \mathrm{Al}_{2} \mathrm{O}_{3}$ катализаторах // Газохимия. 2008. № 4. С. 66-69.

23. Пахомов Н.А. Промышленный катализ в лекциях. М.: Калвис, 2006. № $6.53 \mathrm{c}$. 
24. Пат. 2322290 РФ, МПК В 01 J 23/26, В 01 J 23/10, В 01 J 23/04, В 01 J 21/02, В 01 J 35/02, В 01 J 37/02, С 07 C 5/333, В 82 В 1/00. Катализатор, способ его получения и процесс дегидрирования $\mathrm{C}_{3}-\mathrm{C}_{5}$ парафиновых углеводородов в олефины / В.В. Молчанов, Н.А. Пахомов, Л.А. Исупова. 2006144828/04, Заявлено 18.12.2006; Опубл. 20.04.2008. Бюл. 11.

25. Пат. 2167709 РФ, МПК В 01 J 21/12, В 01 J 23/14, В 01 J 32/00, В 01 J 8/04, С 07 C 5/333. Катализатор для дегидрирования парафиновых углеводородов / Г.Р. Котельников, В.И. Титов, Б.П. Золотовский. 2000104153/04, Заявлено 21.02.2000; Опубл. 27.05.2001. Бюл. 15.

26. Пат. 2517108 РФ, МПК В 01 J 23/14, В 01 J 23/26. Катализатор на основе меди, нанесенный на мезопористый уголь, способ его получения и применения / Лиу Цзинвэй, Чэнь Шаохуэй. 2012136553/04, Заявлено 27.08.2012; Опубл. 27.05.2014. Бюл. 15.

27. Пат. 2402514 РФ, МПК В 01 J 8/04, С 07 С 5/333. Способ получения олефинов $\mathrm{C}_{3}-\mathrm{C}_{5}$ и катализатор для его осуществления / Н.А. Пахомов. 2009112128/04, Заявлено 01.04.2009; Опубл. 27.10.2010. Бюл. 30.

28. Пат. 2350594 РФ, МПК В 01 J 21/04, В 01 J 23/26. Алюмооксидный носитель, способ получения алюмооксидного носителя и способ получения катализатора дегидрирования $\mathrm{C}_{3}-\mathrm{C}_{5}$ парафиновых углеводородов на этом носителе / А.А. Ламберов. Заявлено 13.08.2007; Опубл. 27.03.2009. Бюл. 9.

29. Пат. 2188073 РФ, МПК В 01 J 8/04, С 07 C 5/333. Катализатор для дегидрирования парафиновых углеводородов / Г.Р. Котельников. 2000120139/04, Заявлено 27.07.2000; Опубл. 27.08.2002. Бюл. 24.

30. Пат. 2271860 РФ, МПК В 01 J 23/26, В 01 J 23/04, В 01 J 21/04, В 01 J 21/06, В 01 J 23/70, С 07 C 5/333. Катализатор для дегидрирования парафиновых углеводородов / Т.В. Борисова, О.М. Мельникова. 2005107191/04, Заявлено 15.03.2005; Опубл. 20.03.2006. Бюл. 8.

31. Пат. 2301108 РФ, МПК В 01 J 23/26, В 01 J 37/02. Катализатор для дегидрирования углеводородов и способ его получения / О.А. Парахин, М.П. Чернов. 2006126904/04, Заявлено 20.07.2006; Опубл. 20.06.2007. Бюл. 17. 
32. Кутузов П.И., Баженов Ю.П., Касьянова Л.3., Левченко В.О. Влияние увеличения поверхности контакта на активность железооксидного катализатора дегидрирования // Нефтепереработка и нефтехимия проблемы и перспективы: матер. науч.-практ. конф. Уфа, 2001. С. 262-265.

33. Закумбаева Г.Д., Токтабаева Н.Ф., Бродский А.Р. и др. Дегидрирование алканов состава $\mathrm{C}_{2}-\mathrm{C}_{4}$ на железосодержащих катализаторах // Нефтехимия. 2004. № 2. С. 113-118.

34. Пат. 2486007 РФ, МПК В 01 J 23/14, В 01 J 23/26. Высокопористые пенокерамики как носители катализатора для дегидрирования алканов / Миан Мухаммад Икбал, Хейнриц-Адриан Макс. 2011105458/04, Заявлено 28.07.2009; Опубл. 27.06.2013. Бюл. 18.

35. Sokolov S., Stoyanova M., Rodemerck U., Linke D., Kondratenko E.V. Effect of Support on Selectivity and On-Stream Stability of Surface $\mathrm{VO}_{x}$ Species in Non-Oxidative Propane Dehydrogenation // Catalysis Science and Technology. 2014. № 4. P. 1323-1332.

36. Harlin M.E., Niemi V.M., Krause A.O.I., Weckhuysen B.M.J. Effect of $\mathrm{Mg}$ and $\mathrm{Zr}$ Modification on the Activity of $\mathrm{VO}_{x} / \mathrm{Al}_{2} \mathrm{O}_{3}$ Catalysts in the Dehydrogenation of Butanes // Journal of Catalysis. 2001. № 1. P. 242-252.

37. Harlin M.E., Backman L.B., Krause, A.O.I. Activity of Molybdenum Oxide Catalyst in the Dehydrogenation of n-Butane // Journal of Catalysis. 1999. № 2. P. 300-313.

38. Mitchell P.C.H., Wass S.A. Propane Dehydrogenation over Molybdenum Hydrotalcite Catalysts // Applied Catalysis A: General. 2002. No. 1-2. P. 153-156.

\section{References}

1. Rioux R.M., Song H., Hoefelmeyer J.D., Yang P., Somorjai G.A. HighSurface-Area Catalyst Design: Synthesis, Characterization, and Reaction Studies of Platinum Nanoparticles in Mesoporous. J. Phys. Chem. B., 2005, No. 109 (6), pp. 2192-2202. 
2. Caspary K.J., Gehrke H., Heinritz-Adrian M., Schwefer M. In Handbook of Heterogeneous Catalysis, 2008. pp. 3206-3229.

3. Sanfilippo D. Dehydrogenation of Paraffins: Synergies between Catalyst Design and Reactor Engineering. Catalysis Today, 2006, No. 111. 133 p.

4. Stepanova L.N., Bel'skaya O.B., Likholobov V.A. Sintez i issledovanie katalizatorov $\mathrm{Pt} / \mathrm{MgAlSnO}$ [Synthesis and Research of Pt/MgAlSnO Catalysts]. Khimiya $v$ interesakh ustoichivogo razvitiya - Chemistry for Sustainable Development, 2014, No. 1, pp. 61-68. [in Russian].

5. Vakhmistrov V.E., Ponomarev A.B., Shostakovskii M.V., Kalinin V.N. Katalizator degidrirovaniya, sposob ego polucheniya $i$ sposob polucheniya olefinovykh uglevodorodov $C_{2}-C_{5} \quad s$ ispol'zovaniem etogo katalizatora [Dehydrogenation Catalyst, a Method for its Preparation and a Method for the Production of Olefin Hydrocarbons $\mathrm{C}_{2}-\mathrm{C}_{5}$ using This Catalyst]. Patent RF, No. 2463109, 2012. [in Russian].

6. Voskoboynikov T.V., Adriaan Sachtler J.W., Wei D.H., Vora B.V. Dehydrogenation Catalyst Composition. Patent US, No. 6756340, 2004.

7. Smirnov A.V., Ivanova I.I., Ivanushkin G.G. Katalizator degidrirovaniya szhizhennykh uglevodorodnykh gazov, sposob ego polucheniya i primeneniya [The Catalyst for the Dehydrogenation of Liquefied Petroleum Gas, Method of its Obtaining and Application]. Patent RF, No. 2638171, 2017. [in Russian].

8. Buyanov A.V. Katalizatory i protsessy degidrirovaniya parafinov i olefinov [The Catalysts and Processes of Dehydrogenation of Paraffins and Olefins]. Kinetika i kataliz - Kinetics and Catalysis, 2001, No. 1, pp. 72-85. [in Russian].

9. Karimov O.Kh., Daminev R.R., Kas'yanova L.Z., Karimov E.Kh. Modifitsirovanie alyumooksidnogo nositelya dlya katalizatora degidrirovaniya legkikh uglevodorodov pod deistviem SVCh-polya [Modification of Alumina Carrier for Light Hydrocarbon Dehydrogenation Catalyst under the Action of Microwave Field]. Bashkirskii khimicheskii zhurnal - Bashkir Chemical Journal, 2012, No. 4, pp .7-10. [in Russian]. 
10. Didenko L.P., Kolesnikova A.M., Voronetskii M.S., Savchenko V.I., Domashnev I.A., Sementsova L.A. Alyumokhromovyi katalizator degidrirovaniya propana, prigotovlennyi modifitsirovannym metodom soosazhdeniya [The Chromia-Alumina Catalyst for the Dehydrogenation of Propane Prepared by a Modified Coprecipitation Method]. Kataliz $v$ promyshlennosti - Catalysis in Industry, 2011, No. 2, pp. 7-14. [in Russian].

11. Zhao H., Song H., Xu L., Chou L. Isobutane Dehydrogenation over the Mesoporous $\mathrm{Cr}_{2} \mathrm{O}_{3} / \mathrm{Al}_{2} \mathrm{O}_{3}$ Catalysts Synthesized from a Metal-Organic Framework MIL-101. Applied Catalysis A: General, 2013, No. 456, pp. 188-196.

12. Marcilly C., Delmon B. J. The Activity of True $\mathrm{Cr}_{2} \mathrm{O}_{3} / \mathrm{Al}_{2} \mathrm{O}_{3}$ Solid Solutions in Dehydrogenation. Journal of Catalysis, 1972, No. 2, pp. 336-347.

13. Weckhuysen B.M., Schoonheydt R.A. Alkane Dehydrogenation over Supported Chromium Oxide Catalysts. Catalysis Today, 1999, No. 2, pp. 223-232.

14. Bhasin M.M. Dehydrogenation and Oxydehydrogenation of Paraffins to Olefins. Appl. Catalysis A: General, 2001, Vol. 221, pp. 397-419.

15. Gil'manov Kh.Kh. Primenenie produktov termokhimicheskoi aktivatsii glinozema $\mathrm{v}$ kachestve nositelei mikrosfericheskikh alyumokhromovykh katalizatorov degidrirovaniya $\mathrm{S}_{3}-\mathrm{S}_{5}$ parafinov [Application of Products of Thermochemical Activation of the Alumina as Carriers of a Microspherical Chromia-Alumina Catalysts for the Dehydrogenation of $\mathrm{C}_{3} \mathrm{C}_{5}$ Paraffins]. Vestnik Kazanskogo Tekhnologicheskogo Instituta - Bulletin of the Technological University, 2010, No. 2, pp. 355-363. [in Russian].

16. Nesterov O.N., Egorova S.R., Bekmukhamedov G.E., Kataev A.N., Lamberov A.A., Gil'manov Kh.Kh. Vliyanie kontsentratsii oksidov khroma i kaliya na svoistva mikrosfericheskogo alyumokhromovogo katalizatora degidrirovaniya nizshikh parafinov [The Effect of Concentrations of Oxides of Chromium and Potassium on the Properties of a Microspherical ChromiaAlumina Catalyst for Dehydrogenation of Lower Paraffins]. Vestnik Kazanskogo Tekhnologicheskogo Instituta - Bulletin of the Technological University, 2011, No. 5, pp. 33-39. [in Russian]. 
17. Karimov O.Kh., Daminev R.R., Kas'yanova L.Z., Karimov E.Kh. Sposob prigotovleniya katalizatora dlya degidrirovaniya parafinovykh uglevodorodov [Method of Preparation of Catalyst for Dehydrogenation of Paraffin Hydrocarbons]. Patent RF, No. 2539300, 2014. [in Russian].

18. Karimov O.K., Daminev R.R., Kasyanova L.Z. Increase in Thermostability of Chromia-Alumina Catalysts Used in Dehydrogenation of Paraffines by Means SHF Radiation. Middle East Journal of Scientific Research, 2013, No. 2, pp. 127-130.

19. Karimov O.K., Karimov E.K., Daminev R.R., Kasyanova L.Z., Nasyrov R.R. Power-Efficient Synthesis of Isoprene via Two-Stage Dehydrogenation of Isopentane. World Applied Sciences Journal, 2013, No. 3, pp. 320-325.

20. Kas'yanova L.Z., Karimov O.Kh., Karimov E.Kh. Regulirovanie fizikokhimicheskikh svoistv termoaktivirovannogo trigidrata alyuminiya [Regulation of Physico-Chemical Properties Thermoactivating of Trihydrate of Aluminium]. Bashkirskii khimicheskii zhurnal - Bashkir Chemical Journal, 2014, No. 3, pp. 90-94. [in Russian].

21. Karimov O.Kh., Daminev R.R., Kas'yanova L.Z., Karimov E.Kh., Vakhitova R.R. Issledovanie protsessa sushki alyumokhromovogo katalizatora $v$ elektromagnitnom pole SVCh diapazona [The Study of the Process of Drying Chromia-Alumina Catalyst in the Electromagnetic Field of Microwave Range]. Elektronnyi nauchnyi zhurnal «Neftegazovoe delo» - Electronic Scientific Journal "Oil and Gas Business», 2013, No. 4, pp. 291-301. Available at: www.ogbus.ru/autors/karimovokh/karimovokh_1.pdf (accessed 12.04.2019). [in Russian].

22. Pakhomov N.A. Degidrirovanie parafinov $\mathrm{C}_{2}-\mathrm{C}_{4}$ na $\mathrm{Cr}_{2} \mathrm{O}_{3} / \mathrm{Al}_{2} \mathrm{O}_{3}$ katalizatorakh [Dehydrogenation of $\mathrm{C}_{2}-\mathrm{C}_{4}$ Paraffins on $\mathrm{Cr}_{2} \mathrm{O}_{3} / \mathrm{Al}_{2} \mathrm{O}_{3}$ Catalysts]. Gazokhimiya - Gazokhimiya, 2008, No. 4, pp. 66-69. [in Russian].

23. Pakhomov N.A. Promyshlennyi kataliz v lektsiyakh [Industrial Catalysis in Lectures]. Moscow, Kalvis, 2006, No. 6, 53 p. [in Russian]. 
24. Molchanov V.V., Pakhomov N.A., Isupova L.A. Katalizator, sposob ego polucheniya i protsess degidrirovaniya $S_{3}-S_{5}$ parafinovykh uglevodorodov v olefiny [Catalyst, Method of its Preparation and Process of Dehydrogenation of $\mathrm{C}_{3}-\mathrm{C}_{5}$ Paraffinic Hydrocarbons into Olefins]. Patent RF, No. 2322290, 2008. [in Russian].

25. Kotel'nikov G.R., Titov V.I., Zolotovskii B.P. Katalizator dlya degidrirovaniya parafinovykh uglevodorodov [Catalyst for Dehydrogenation of Paraffinic Hydrocarbons]. Patent RF, No. 2167709, 2001. [in Russian].

26. Tszinvei Liu, Shaokhuei Chen'. Katalizator na osnove medi, nanesennyi na mezoporistyi ugol', sposob ego polucheniya i primeneniya [A Catalyst Based on Copper, Deposited on Mesoporous Carbon, Method of its Obtaining and Application]. Patent RF, No. 2517108, 2014. [in Russian].

27. Pakhomov N.A. Sposob polucheniya olefinov $S_{3}-S_{5}$ i katalizator dlya ego osushchestvleniya [Method for Producing Olefins $\mathrm{C}_{3}-\mathrm{C}_{5}$ and Catalyst for its Implementation]. Patent RF, No. 2402514, 2010. [in Russian].

28. Lamberov A.A. Alyumooksidnyi nositel', sposob polucheniya alyumooksidnogo nositelya i sposob polucheniya katalizatora degidrirovaniya $C_{3}-C_{5}$ parafinovykh uglevodorodov na etom nositele [Aluminum Oxide Carrier, a Method for Producing an Aluminum Oxide Carrier and a Method for Producing a Catalyst for Dehydrogenation of $\mathrm{C}_{3}-\mathrm{C}_{5}$ Paraffinic Hydrocarbons on this Carrier]. Patent RF, No. 2350594, 2009. [in Russian].

29. Kotel'nikov G.R. Katalizator dlya degidrirovaniya parafinovykh uglevodorodov [Catalyst for Dehydrogenation of Paraffinic Hydrocarbons]. Patent RF, No. 2188073, 2002. [in Russian].

30. Borisova T.V., Mel'nikova O.M. Katalizator dlya degidrirovaniya parafinovykh uglevodorodov [Catalyst for Dehydrogenation of Paraffinic Hydrocarbons]. Patent RF, No. 2271860, 2006. [in Russian].

31. Parakhin O.A., Chernov M.P. Katalizator dlya degidrirovaniya uglevodorodov $i$ sposob ego polucheniya [Catalyst for Dehydrogenation of Hydrocarbons and Method of its Production]. Patent RF, No. 2301108, 2007. [in Russian]. 
32. Kutuzov P.I., Bazhenov Yu.P., Kas'yanova L.Z., Levchenko V.O. Vliyanie uvelicheniya poverkhnosti kontakta na aktivnost' zhelezooksidnogo katalizatora degidrirovaniya [Effect of Increasing the Contact Surface on the Activity of Iron Oxide Dehydrogenation Catalyst]. Materialy nauchnoprakticheskoi konferentsii «Neftepererabotka $i$ neftekhimiya - problemy $i$ perspektivy» [Materials of Scientific and Practical Conference «Oil Refining and Petrochemistry - Problems and Prospects»]. Ufa, 2001. pp. 262-265. [in Russian].

33. Zakumbaeva G.D., Toktabaeva N.F., Brodskii A.R. e.a. Degidrirovanie alkanov sostava $\mathrm{S}_{2}-\mathrm{S}_{4}$ na zhelezosoderzhashchikh katalizatorakh [Dehydrogenation of $\mathrm{C}_{2}-\mathrm{C}_{4}$ Alkanes on Iron-Containing Catalysts]. Neftegazochimiya - Oil and Gas Chemistry, 2004, No. 2, pp. 113-118. [in Russian].

34. Mian Mukhammad Ikbal, Kheinrits-Adrian Maks. Vysokoporistye penokeramiki kak nositeli katalizatora dlya degidrirovaniya alkanov [Highly Porous Foam Ceramics as Catalyst Carriers for Dehydrogenation of Alkanes]. Patent RF, No. 2486007, 2013. [in Russian].

35. Sokolov S., Stoyanova M., Rodemerck U., Linke D., Kondratenko E.V. Effect of Support on Selectivity and On-Stream Stability of Surface $\mathrm{VO}_{x}$ Species in Non-Oxidative Propane Dehydrogenation. Catalysis Science and Technology, 2014, No. 4, pp. 1323-1332.

36. Harlin M.E., Niemi V.M., Krause A.O.I., Weckhuysen B.M.J. Effect of $\mathrm{Mg}$ and $\mathrm{Zr}$ Modification on the Activity of $\mathrm{VO}_{x} / \mathrm{Al}_{2} \mathrm{O}_{3}$ Catalysts in the Dehydrogenation of Butanes. Journal of Catalysis, 2001, No. 1, pp. 242-252.

37. Harlin M.E., Backman L.B., Krause, A.O.I. Activity of Molybdenum Oxide Catalyst in the Dehydrogenation of n-Butane. Journal of Catalysis, 1999, No. 2, pp. 300-313.

38. Mitchell P.C.H., Wass S.A. Propane Dehydrogenation over Molybdenum Hydrotalcite Catalysts. Applied Catalysis A: Genereal, 2002, No. 1-2, pp. 153-156. 


\section{Сведения об авторах}

\section{About the authors}

Байрамгулова Резеда Ильгизовна, магистрант кафедры «Газохимия и моделирование химико-технологических процессов», УГНТУ, г. Уфа, Российская Федерация

Rezeda I. Bairamgulova, Undergraduate Student of Gas Chemistry and Modeling of Chemical Engineering Processes Department, USPTU, Ufa, Russian Federation

e-mail: rezeda_bairamgulova@mail.ru

Трапезникова Елена Фанисовна, канд. техн. наук, доцент кафедры «Газохимия и моделирование химико-технологических процессов», УГНТУ, г. Уфа, Российская Федерация

Elena F. Trapeznikova, Candidate of Engineering Sciences, Assistant Professor of Gas Chemistry and Modeling of Chemical Engineering Processes Department, USPTU, Ufa, Russian Federation

e-mail: gmchtp@mail.ru 